Soichiro Inoue MD,* Ryousuke Ishii MD,* Hirokazu Fukuda MD, $\uparrow$ Kazuhiko Saitoh MD, $\dagger$ Reiju Shimizu MD†

\title{
Sevoflurane anaesthesia for a patient with adult polyglucosan body disease
}

Purpose: Adult polyglucosan body disease (APBD) is a rare neurological disorder of unknown cause characterized by four manifestations: upper motor neuron signs, peripheral neuropathy with motor and sensory loss, urinary incontinence, and dementia. The purpose of this report is to present a patient with $A P B D$ anaesthetized successfully with sevoflurane and nitrous oxide.

Clinical feature: A 51-yr-old man with APBD was scheduled for haemorrhoidectomy. Paraesthesia, dysaesthesia, distal muscular atrophy and fasciculation were recognized in the extremities. Dementia, bulbar paralysis and respiratory insufficiency were absent. Anaesthesia was induced with inhalation of sevoflurane and nitrous oxide, and the trachea was intubated without the use of muscle relaxants. Maintenance of anaesthesia was performed with sevoflurane (inspired concentration: 1.5-2.5\%) and nitrous oxide (50\%). Emergence from anaesthesia and the postoperative course were uneventful, and no exacerbation of neurological signs and symptoms was recognized. No postoperative analgesia was required.

Conclusion: General anaesthesia and tracheal intubation with sevoflurane and nitrous oxide provided safe anaesthesia for a patient with $A P B D$.

Objectif: La maladie adulte des corps polysaccharidiques (MACP) est une affection neurologique rare de cause inconnue caractérisée par quatre manifestations: des signes

\section{Key words}

ANAESTHETICS, VOLATILE: sevoflurane;

COMPLICATIONS: peripheral neuropathy;

METABOLISM: polyglucosan body;

SYNDROME: adult polyglucosan body disease.

From The Department of Anaesthesia, Omiya Red Cross Hospital, Saitama, Japan* and the Department of Anaesthesiology, Jichi Medical School, Tochigi, Japan†.

Address correspondence to: Dr. Soichiro Inoue,

The Department of Anaesthesiology, Jichi Medical School,

3311-1 Yakushiji, Kawachi-gun, Tochigi, 329-04, Japan,

Phone: +81-285-44-2111. Fax: +81-285-44-4108.

Accepted for publication July 28, 1996. d'atteinte du neurone moteur supérieur, une neuropathie périphérique avec perte de motricité et de sensibilité, de l'incontinence urinaire et de la démence. Cette observation vise à présenter un patient souffrant de MACP anesthésié avec succès au sévoflurane et au protoxyde d'azote.

Éléments cliniques: Un homme de 51 ans souffrant de MACP est programmé pour hémorrhoïdectomie. On constate des paresthésies, des dysesthésies, de l'atrophie musculaire distale et des fasciculations aux extrémités. Il ne présente pas de démence, de paralysie bulbaire ou d'insuffisance respiratoire. L'anesthésie est induite au sévoflurane et au protoxyde d'azote en inhalation. La trachée est intubée sans myorelaxants. L'anesthésie est maintenue au sévoflurane (concentration inspirée 1,5-2,5\%) et au protoxyde d'azote (50\%). Le réveil et l'évolution postopératoire se déroulent sans incidents. L'analgésie postopératoire n'est pas requise.

Conclusion: L'anesthésie générale et l'intubation trachéale ont été réalisées en toute sécurité chez un patient souffrant de $M A C P$.

Adult polyglucosan body disease (APBD) is a rare neurological disorder characterized by progressive involvement of the upper and lower motor neurons, sensory loss predominantly in the legs, early neurogenic bladder and, in some cases, late dementia. ${ }^{1-4}$ Pathologically, there is accumulation of intraaxonal polyglucosan bodies (PBs) in the central and peripheral nervous systems. ${ }^{1-5}$ Polyglucosan bodies are composed principally of glucose polymers and stain intensely with periodic acid-Schiff (PAS). ${ }^{1,4,5}$ This is the first report of anaesthesia for a patient with APBD.

\section{Case report}

A 51-yr-old, $75 \mathrm{~kg}$ man, was scheduled for haemorrhoidectomy. At the age of $36 \mathrm{yr}$, he first noticed weakness and atrophy of the left arm. Within three years, all extremities became weak and fasciculations were seen in the left arm. Loss of sensation in the extremities and urge incontinence of urine and feces manifested themselves. His gait became awkward and he fell frequently. At the age of $40 \mathrm{yr}$, neurogenic changes were shown by 
electromyography. Although motor conduction velocity of the right peroneal nerve was not detected, sensory nerve conduction velocity of the left median nerve was $27.7 \mathrm{~m} \cdot \mathrm{sec}^{-1}$ (normal: $60.73 \pm 3.79 \mathrm{~m} \cdot \mathrm{sec}^{-1}$ ). Then, he was diagnosed as APBD by accumulation of PBs in the sural nerve biopsy. He had no family history of neurological disease.

On preanaesthetic examination, he was alert and oriented. Cranial nerve function was normal except for sensory loss in the left face. There were no bulbar symptoms. He complained of paraesthesia and dysaesthesia in the legs and the distal part of the left arm. Distal muscular atrophy of all extremities and fasciculation in the left hand were recognized. Pain and temperature perception were blunted below the level of $T_{4}$ and in the distal part of the left arm. Vibration perception was blunted in the ankles and the left wrist. Abdominal reflexes were present; deep tendon reflexes of the left arm and the legs were reduced. Routine haematological and biochemical tests were normal. Forced vital capacity was $3,440 \mathrm{ml}$ (93\% of predicted) and forced expiratory volume at one second was $2,710 \mathrm{ml}$ ( $81 \%$ of predicted).

At the age of 45 and $49 \mathrm{yr}$, he had received spinal anaesthesia for haemorrhoidectomy, and this was not followed by exacerbation of neurological signs and symptoms. This time he requested general anaesthesia.

Atropine $0.5 \mathrm{mg}$ was administered $30 \mathrm{~min}$ before induction of anaesthesia with sevoflurane and $50 \%$ of nitrous oxide in oxygen. The inspired concentration of sevoflurane was increased from $0.5 \%$ initially by $1 \%$ every three to five breaths up to $5 \%$. Five minutes later, laryngotracheal lidocaine was administered and the trachea was intubated without muscle relaxants. The position of the vocal cords was open and no adverse reactions occurred during induction. Anaesthesia was maintained with $50 \%$ nitrous oxide and $1.5-2.5 \%$ sevoflurane in oxygen. Monitors included ECG, non-invasive automatic arterial manometer, an oesophageal thermometer, pulse oximeter and capnograph. Inspired and end-tidal concentrations of nitrous oxide and sevoflurane were measured with a Datex Capnomac Ultima ${ }^{\circledR}$ monitor (Helsinki, Finland). At the end of surgery, anaesthetic agents were discontinued. Seven minutes later, the patient opened his eyes and responded to verbal commands, and the trachea was extubated. Emergence from anaesthesia was uneventful and no analgesia was required because of characteristics of APBD. The postoperative course were uneventful and no exacerbation of neurological signs or symptoms was recognized.

\section{Discussion}

General anaesthesia and tracheal intubation were per- formed uneventfully with nitrous oxide and sevoflurane in a patient with APBD. In this rare progressive neurological disorder, the diagnosis is based on the demonstration of intraaxonal PBs in the peripheral or central nerve. ${ }^{3,5}$ However, PBs are not specific to APBD: they may occur in the normal course of aging as well as in some neurological disorders. ${ }^{1}$ Although branching enzyme deficiency was reported in some patients, the pathogenesis of APBD is unclear. ${ }^{5,6}$

In a patient with progressive neurological disease, there is concern about the risk of exacerbating co-existing neurological symptom with regional anaesthesia. We chose general anaesthesia, because the patient refused to be awake during surgery and there was no evidence of bulbar paralysis or respiratory insufficiency. In patients with neurological disorders involving motor deficits, succinylcholine is contraindicated ${ }^{7}$ and nondepolarizing muscle relaxants must be used cautiously because of uncertainty about the duration of muscle paralysis. Muscle relaxants were not used to facilitate tracheal intubation.

Since there are no reports of anaesthesia for patients with APBD and it is uncertain how intravenous anaesthetic agents affect the nervous system in such progressive diseases, induction and maintenance of anaesthesia should be simple to avoid abnormal reactions. The concentration of intravenous agents cannot be monitored clinically, whereas inspired and end-tidal concentrations of inhaled anaesthetics can be easily measured. Therefore, inhalation anaesthesia was selected. Inhalation of sevoflurane has been desirable for induction of anaesthesia in children and adults. ${ }^{8,9}$ Because of its pleasant, nonirritating odour and lack of pungency, it is successful. Sevoflurane also provides sufficient muscle relaxation to facilitate tracheal intubation. ${ }^{10.11}$ Although Kimura et al. ${ }^{11}$ reported that the $\mathrm{ED}_{95}$ of sevoflurane for tracheal intubation in adults was $8.07 \%$, tracheal intubation was accomplished with sevoflurane $5 \%$ in this patient. The addition of nitrous oxide during induction and laryngotracheal lidocaine before tracheal intubation may have reduced the sevoflurane requirement.

In summary, general anaesthesia with sevoflurane and nitrous oxide provided satisfactory conditions for surgery in a patient with APBD.

\section{References}

1 Robitaille Y, Carpenter S, Karpati G, DiMauro S. A distinct form of adult polyglucosan body disease with massive involvement of central and peripheral neuronal processes and astrocytes. A report of four cases and a review of the occurrence of polyglucosan bodies in other conditions such as Lafora's disease and normal aging. Brain 1980; 103: 315-36. 
2 Okamoto K, Llena JF, Hirano A. A type of adult polyglucosan body disease. Acta Neuropathol (Berl) 1982; 58: 73-7.

3 Vos AJM, Joosten EMG, Gabreëls-Festen AAWM. Adult polyglucosan body disease: clinical and nerve biopsy findings in two cases. Ann Neurol 1983; 13:440-4.

4 Gray F, Gherardi R, Marshall A, Janota I, Poirier J. Adult polyglucosan body disease (APBD). J Neuropathol Exp Neurol 1988; 47: 459-74.

5 Bruno C, Servidei S, Shanske S, et al. Glycogen branching enzyme deficiency in adult polyglucosan body disease. Ann Neurol 1993; 33: 88-93.

6 Lossos A, Barash V, Soffer D, et al. Hereditary branching enzyme dysfunction in adult polyglucosan body disease: a possible metabolic cause in two patients. Ann Neurol 1991; 30: 655-62.

7 Gronert GA, Theye RA. Pathophysiology of hyperkalemia induced by succinylcholine. Anesthesiology 1975; 43: 89-99.

8 Holaday DA, Smith FR. Clinical characteristics and biotransformation of sevoflurane in healthy human volunteers. Anesthesiology 1981; 54: 100-6.

9 Sarner JB, Levine M, Davis PJ, Lerman J, Cook DR, Motoyama EK. Clinical characteristics of sevoflurane in children. A comparison with halothane. Anesthesiology 1995; 82: 38-46.

10 Eger EI II. New inhaled anesthetics. Anesthesiology 1994; 80: 906-22.

11 Kimura $T$, Watanabe $S$, Asakura $N$, Inomata $S$, Okada $M$, Taguchi $M$. Determination of end-tidal sevoflurane concentration for tracheal intubation and minimum alveolar anesthetic concentration in adults. Anesth Analg 1994; 79: $378-81$. 